\title{
Direitos sexuais e reprodutivos: desafios para as políticas de saúde
}

\author{
Sexual and reproductive rights: challenges for \\ health policies
}

1 SOS CORPO - Gênero e Cidadania. Rua Real da Torre 593, Recife, $P E$ 50610-000, Brasil. betania@soscorpo.org.br

\begin{abstract}
This article discusses sexual and reproductive rights in the sense of a stance that assumes a perspective of transformations in social relations, the struggle against prejudices, the guarantee of well-being, and finally the relationship between sexuality, reproduction, and citizenship. The article then proceeds to reflect on health policy challenges in these fields, emphasizing such issues as: guaranteed resources, quality and quantity of health services in response to demands by the population, and cultural changes that produce a new view of the relationship between health professionals and health system clients, based on the principles of citizenship: recognition others as entitled to freedom and equality.
\end{abstract}

Key words Professional-Patient Relations; Sexuality; Gender

Resumo São desenvolvidas algumas considerações sobre direitos reprodutivos e direitos sexuais, no sentido de colocar um posicionamento sobre eles na perspectiva transformadora das relações sociais, da luta contra os preconceitos, da garantia do bem-estar e finalmente, da relação entre sexualidade, reprodução e cidadania. Em um segundo momento são feitas algumas reflexões sobre os desafios para uma política de saúde nestes campos, onde são enfatizadas questões como: garantia de recursos, qualidade e quantidade de serviços de saúde que respondam às demandas da população e mudanças culturais que produzam uma nova visão sobre a relação entre profissionais de saúde e usuárias/as, baseadas nos princípios da cidadania: reconhecimento do outro como sujeito dotado de liberdade e igualdade.

Palavras-chave Relações Profissional-Paciente; Sexualidade; Gênero 
Para chegarmos aos desafios de uma política pública de saúde concernente ao campo dos direitos reprodutivos e direitos sexuais, colocase como necessário apresentarmos antes algumas considerações sobre esses conceitos. Isso porque como em qualquer outro caso, os direitos podem ter várias abordagens dependendo da visão teórico-política com base na qual são colocados em perspectiva.

$\mathrm{O}$ feminismo lançou os questionamentos e a idéias que vão historicamente produzir o conceito de direitos reprodutivos e servir de base para a construção de direitos sexuais. Pode-se dizer que no primeiro caso há uma autoria original do feminismo, e no segundo uma autoria compartilhada entre vários movimentos sociais, sendo os mais relevantes o movimento gay, o movimento lésbico e o movimento feminista. Hoje, esses conceitos estão amplamente utilizados, pode-se mesmo afirmar que há uma disputa de significados em torno deles, que engloba muitos outros atores e sujeitos para além desses que estão ligados a suas origens.

Isto quer dizer que esses direitos estão reconhecidos como valores democráticos e estão na agenda política dos contextos nacionais e internacionais.

Na perspectiva feminista aqui adotada, os direitos reprodutivos dizem respeito à igualdade e à liberdade na esfera da vida reprodutiva. Os direitos sexuais dizem respeito à igualdade e à liberdade no exercício da sexualidade. O que significa tratar sexualidade e reprodução como dimensões da cidadania e conseqüentemente da vida democrática.

Tratá-los como dois campos separados é uma questão crucial no sentido de assegurar a autonomia dessas duas esferas da vida, o que permite relacioná-los entre si e com várias outras dimensões da vida social. É também um reconhecimento das razões históricas que levaram o feminismo a defender a liberdade sexual das mulheres como diretamente relacionada à sua autonomia de decisão na vida reprodutiva. A luta no campo ideológico para romper com a moral conservadora, que prescrevia para as mulheres a submissão da sexualidade à reprodução, teve um significado muito forte na história da prática política e do pensamento feministas. E continua tendo. Essa mesma moral é também definidora da heterossexualidade como expressão "natural" de relacionamento sexual e como a única que deveria ser aceita socialmente. A heterossexualidade como norma foi o esteio desse modelo de sexualidade baseado em sexo-procriação. Meios repressivos foram historicamente instaurados para mantê-lo como comportamento hegemônico.
Isto é, a heterossexualidade como forma "natural" de relação foi garantida por meio da repressão sexual às outras formas de expressão sexual. É justamente contra essa visão moral que os movimentos gay e lésbico formam suas lutas e aportam sua contribuição estratégica para a emergência dos direitos sexuais em uma relação política com o movimento feminista. Para os movimentos de gays e de lésbicas, essa é uma questão central na configuração de novos sentidos para a cidadania. De uma certa forma, há uma recuperação das reflexões e lutas originais do feminismo contemporâneo, superando-se (em sentido dialético) a centralidade da heterossexual que pautava, na origem, as manifestações por liberdade sexual e reprodutiva.

Considero de grande importância tratar esses direitos no sentido libertário e igualitário, e não no sentido prescritivo de constituição de um modelo e regras para o exercício da sexualidade e da vida reprodutiva. E dessa forma, também contradizer a tradição que regulamentou e normatizou - no sentido repressivo e discriminador - a sexualidade e a reprodução. Contradizer também uma "modernidade" mercadológica que propõe uma concepção de sexualidade e de reprodução livres com base na lógica do mercado, a partir da qual todas as relações da vida social são reduzidas a operações mercantilistas. Os agentes dessa ideologia de mercado produzem um discurso que perverte o sentido da cidadania ao colocar o consumo como a nova forma de acesso à liberdade, reduzindo o sentido da vida à possibilidade de consumir. Os meios midiáticos são usados, a exaustão, para uma persuasão que leve ao consumo, o que leva as pessoas a buscar os desejos produzidos pelo mercado. Na igualdade propalada pelo mercado, homens e mulheres são iguais pela redução dos dois a objetos.

O que considero de especial relevância é que ao não pensar esses direitos como prescrições de modelos sobre sexualidade e reprodução, devemos abordá-los como campos éticos. E também compreender a relação entre direitos e poder. E sobre esses campos, encontro em Marilena Chauí (1998), referências que nos trazem luzes sobre os sentidos que quero trazer para esses conceitos.

"O agente ético é pensado como sujeito ético, isto é, como um ser racional e consciente que sabe o que faz, como um ser livre que decide e escolhe o que faz, e como um ser responsável que responde pelo que faz. ...Enfim, a ação só é ética se realizar a natureza racional, livre e responsável do agente e se o agente respeitar a racionalidade, liberdade e responsabilidades dos 
outros agentes, de sorte que a subjetividade ética é uma intersubjetividade. A subjetividade e a intersubjetividade éticas são ações e a ética é que existe pela e na ação dos sujeitos individuais e sociais, definidos por laços e formas de sociabilidade criados também pela ação humana em condições históricas determinadas" (Chauí, 1998:33). A questão da autonomia é também colocada por essa autora como um elemento central da liberdade que constitui o agente ético.

Segundo Chauí (1998), baseando-se no que ela diz ser o núcleo do pensamento espinosiano - ter direitos é também ter poder. Portanto um direito não é concedido, mas algo que é conquistado e conservado, porque ele é um poder. Chauí (2003:22-23), partindo daí, diz que nesses termos, "na sociedade brasileira, a maioria da população está desprovida de direitos porque está desprovida de poderes. E que portanto, o processo político no Brasil, ao ser um processo de criação de direitos, é um processo de constituição de poderes, populares, sociais, culturais que se exprimem como poderes políticos. Nós estamos num processo de constituição dos direitos-poderes, mas nós não os temos ainda. O que temos é aquilo que ainda classicamente se chama a democracia formal. Mas é preciso uma democracia social e cultural".

Compreendo que o processo de construção dos direitos reprodutivos e direitos sexuais se integra ao processo mais amplo do movimento dialético de construção da democracia. Para as mulheres, a condição de sujeito construtores de direitos, e nesse caso construtoras de direitos reprodutivos e direitos sexuais, significa romper com a heteronomia a que sempre estiveram submetidas, em relação ao uso de seus próprios corpos, uma vez que todas as regras e tabus que controlaram e reprimiram suas vivências corporais na sexualidade e na reprodução foram historicamente determinadas pelos homens. Essa repressão e esse controle do corpo e da sexualidade são elementos centrais da dominação patriarcal e da sua reprodução.

É importante ressaltar que a persistente desigualdade entre homens e mulheres é um impedimento para a liberdade reprodutiva e sexual das mulheres. A violência na vida cotidiana tem sido um forte mecanismo de manutenção da dominação sobre a vida sexual das mulheres. No terreno político, há uma forte reação por parte dos setores conservadores contra as propostas feministas de transformação social e cultural nestes campos. Um exemplo contundente é a reação contrária à legalização do aborto. Essa reação produz alianças entre igre- jas, partidos políticos e outros setores no sentido de conter avanços no campo legal e das políticas sociais.

Mais recentemente, temos assistido ao surgimento de homens organizados que defendem os direitos reprodutivos para as mulheres e também a extensão desses direitos para os homens. Os homens organizados que defendem essa proposição também estão se contrapondo ao modelo patriarcal ainda hegemônico. A relação dos homens frente à sexualidade e à reprodução está inscrita em um padrão de relações sociais baseado na desigualdade de gênero, e a alteração desse padrão é uma ruptura com essa ordem do poder patriarcal instituída pelos próprios homens. A questão do poder é um campo a ser explorado nas discussões políticas sobre esses direitos na perspectiva feminista. Esse modelo hegemônico distancia os homens dos cuidados paternais e os libera da responsabilidade com a prevenção da gravidez indesejada e também das doenças sexualmente transmissíveis. Alterar esse modelo significa buscar uma sociabilidade na qual o sentido da paternidade e da maternidade sejam completamente transformados, levando a uma divisão sexual igualitária do trabalho no âmbito doméstico e em particular nas tarefas de cuidar das crianças na vida cotidiana. Assumir a responsabilidade e a divisão de tarefas na contracepção, prevenção de doenças sexualmente transmissíveis e certamente em todas as outras dimensões da vida reprodutiva. Não se trata portanto de garantir a inclusão dos homens nos direitos reprodutivos, mas os direitos reprodutivos significam uma transformação de uma forma de inserção dos homens na esfera reprodutiva. A transformação cultural é uma dimensão estratégica para produção de uma nova forma de relação entre os homens e as mulheres com base nos direitos reprodutivos.

Direitos sexuais ao colocar as relações sexuais como relações sociais a serem consideradas no plano da cidadania, a serem portanto mediadas e garantidas nas necessidades que produzem por meio de direitos, colocam a heterossexualidade e a homossexualidade como práticas sexuais igualmente livres. A meu ver é necessário romper com uma concepção de prática sexual como elemento identitário do ponto de vista da inserção social das pessoas. Considero que o fato de isso estar presente como elemento de definição das pessoas ainda revela uma visão de "exceção" em relação à homossexualidade, uma vez que é em relação à prática homossexual que a expressão sexual de alguém se torna uma identificação social. Algo que é descrito como marca de alguém. Ser he- 
terossexual ou homossexual é uma questão da vida privada, que de um lado não pode ser uma questão secreta, no sentido de ser interditada de aparecer socialmente, mas por outro, não deve se tornar necessariamente uma identificação pública de alguém.

Diferentemente são as organizações políticas identificadas como movimentos gay, lésbico, etc. Nesses casos são identidades construídas politicamente, na luta pela conquista de direitos específicos, para transformar a realidade social. Penso que parte dessa transformação é justamente superar a atitude social de identificar as pessoas pela sua expressão sexual, o que ocorre ainda com conotações de julgamento.

\section{Desafios para as políticas de saúde}

Para o exercício efetivo desses direitos, tornase necessário uma transformação da lógica na qual está baseada o sentido das leis que dizem respeito ao exercício da reprodução e das relações amorosas e sexuais. Uma transformação que vai no sentido de deslocar o princípio lógico da prescrição e controle, para o princípio da ética e da liberdade. Políticas públicas dirigidas a esses direitos devem estar voltadas para a justiça social, e para isso, elas têm de ser formuladas e executadas levando em conta as desigualdades de gênero, de classe, de raça e de expressão sexual. A transformação de mentalidade é um processo incontornável para vivência desses direitos. Chego mesmo a afirmar que os direitos sexuais e os direitos reprodutivos trazem consigo a prerrogativa de a construção de um novo imaginário social sobre os temas dos quais eles tratam.

A demanda por políticas sociais na área da saúde constitui um campo de ação estratégico para os sujeitos que defendem os direitos reprodutivos e sexuais.

A relação entre saúde e direitos reprodutivos e sexuais nos leva a pensar sobre essa relação com base nas necessidades geradas pela vivência reprodutiva e pelo exercício da sexualidade. Dito de outra maneira, a reprodução e a sexualidade devem constar como áreas específicas da política geral de saúde pública. Gravidez, parto, puerpério, aleitamento materno, concepção, contracepção, aborto, doenças sexualmente transmissíveis e violência sexual são questões cruciais que hoje estão colocadas para a política de saúde. Isso significa que o poder público deve assegurar nestes campos os meios de promover bem-estar, de prevenir contra morbi-mortalidade e de assegurar trata- mentos e curas necessários. Esse bem-estar diz respeito ao estado de saúde física e mental.

Uma política pública de saúde comprometida com a promoção integral dos direitos reprodutivos e sexuais representará uma conquista política para democracia. Fortalecerá o processo de democratização da sociedade brasileira, contribuindo para superar suas heranças autoritárias, patriarcais e homofóbicas. Contribuirá também, para alterar os limites impostos pelo Estado à vida privada e assim contribuirá para uma cidadania que se estende à vida cotidiana. É importante lembrar a influência do poder e saber médicos nas definições tradicionais das regras que serviram para reprimir e controlar as vivências sexual e reprodutiva. Influência que se deu tanto no âmbito da instituição familiar quanto dos serviços de saúde. O saber no campo da saúde ao se deslocar do lugar de sustentação da repressão para o lugar de garantia de direitos passa por um processo de transformação. Estamos portanto, tratando de superar processos que levem a uma democratização da vida social.

$\mathrm{Na}$ América Latina e no Brasil em particular, a saúde como dimensão da política pública tem sido um tema central para todos os setores que trabalham e agem politicamente em torno dos direitos reprodutivos e dos direitos sexuais. A demanda por políticas de saúde como base para o exercício desses direitos é tão intensa e priorizada pelos movimentos sociais, que produziu em um determinado momento uma restrição na compreensão desses direitos como exclusivos ao campo da saúde enquanto direitos sociais. Neste sentido, é fundamental fortalecer a importância da saúde e ao mesmo tempo afirmar a relação desses direitos com outras esferas da política pública e da vida social.

A demanda por políticas sociais na área da saúde está baseada em uma visão de direitos reprodutivos e sexuais como parte dos direitos sociais, como defesa de um Estado promotor de bem-estar e de transformação social. A cidadania tem sido trabalhada como instrumento de combate à desigualdade social, à conquista de direitos e como um meio de instituir um novo processo democrático assentado sobre o compromisso com a justiça social, com a ética e com uma moral que seja instauradora da dignidade humana, como valor coletivo que promova a superação dos preconceitos e discriminações.

São exemplares dessa configuração a luta pelo Programa de Assistência Integral à Saúde da Mulher e a luta por uma política de saúde voltada para HIV/AIDS.

Os desafios estão em vários níveis e vou salientar os que considero de imediato como es- 
tratégicos. No campo econômico, se coloca a necessidade incontornável de mudança para uma política econômica redestributiva que assegure recursos suficientes na promoção do bem-estar social. Junto com isso vem, em muitos casos, a reconstrução do setor público de saúde dotando-o de meios físicos adequados, tecnologia e recursos humanos que respondam com eficiência aos problemas da população. Sobre os recursos humanos quero salientar a questão da formação em dois sentidos: a formação técnica para lidar com reprodução e questões da sexualidade, mas a formação enquanto consciência de cidadania que implica o se reconhecer e reconhecer o/a outro/a como cidadão/ã. Há nesse campo um desafio específico no plano cultural/ideológico que é o de romper com o conservadorismo e o preconceito que não só discriminam socialmente, mas afetam a saúde física e mental das pessoas e as vulnerabilizam. O preconceito não pode fazer parte da relação entre os profissionais da saúde e os/as usuários/as dos serviços. Se e quando isso acontece ocorrem dois graves problemas. Em primeiro lugar, a pessoa vítima do preconceito vai ter um prejuízo para sua saúde físi- ca e mental. Em segundo, sem ordem de prioridade, no instante que isso acontece ocorre uma violação dos direitos humanos, sem os quais não existe a realização da cidadania. Os tabus e os preconceitos sobre a vida sexual e reprodutiva ao longo da história recente, têm se constituído em um impedimento para uma atenção integral de qualidade nesses terrenos. Tornar a prática preventiva uma rotina que leve de fato à preservação e à promoção da saúde, invertendo o quadro atual de saúde da população, é um desafio que exige uma estratégia de educação para saúde voltada para a qualificação dos profissionais e também como parte da atenção à saúde prestada à população em geral.

Por último, quero ressaltar o desafio de o poder público reconhecer que as políticas de saúde voltadas para reprodução e sexualidade devem ser consideradas como parte das atribuições de um Estado laico e democrático, e portanto, suas ações devem responder à garantia dos direitos da população e, neste sentido não podem ser formuladas nem implantadas segundo as normas e os preceitos de qualquer religião.

\section{Referências}

CHAUÍ, M., 1998. Ética e violência. Teoria e Debate, 39:33-34.

CHAUÍ, M., 2003. Entrevista concedida a Fernando Eichenberg. Primeira Leitura, 17:22-23.

Recebido em 25 de agosto de 2003

Aprovado em 2 de setembro de 2003 